\title{
Kadın Duyarlı Ulaşım Önceliklerinin Belirlenmesi ve Politika Üretimi: Ankara Örneği
}

DOI: $10.26466 /$ opus.632122

\author{
* \\ Hatice Gül Önder * \\ * Dr. Öğr. Gör., Ankara Hacı Bayram Veli Üniversitesi, Ankara / Türkiye \\ E-Posta: gul.onder@hbv.edu.tr \\ ORCID: $\underline{0000-0002-4794-6923}$

\section{Öz}

Günümüzde, kentsel ulaşımda harcanan zaman, kent fizik mekânı açısından bakıldığında, arazi kullanımı ve ulaştırma altyapısının gelişmişliğine göre değişkenlik göstermektedir. Birey açısından bakıldığıında, yolculuk süresindeki farklılığın en önemli göstergesi, cinsiyet, yaş grubu, kullanılan ulaşım türü, yolculuk zinciri ve yolculuk amacı olarak kabul edilebilir. Farklı yaş gruplarındaki kadın ve erkekler, farklı yolculuk amaçlarıla, farklı ulaşım türlerini kullanarak, farklı sürelerde yolculuk gerçekleştirmektedir. Yerel yönetimler bu farklılıkları göz ardı ederek her bireyin benzer şekilde kent içi hareketlilikte bulunduğunu varsayarak, erkek egemen bir toplumu öncelik gözeterek belirli bir düzeyde toplu taşıma hizmeti sunmaktadırlar. Bu durum kadınların gün içi hareketliliklerini olumsuz etkilemekte ve kadının kent hayatına katılımını ve kentteki hareketliliğini kısıtlamaktadır. Bu çalışma, kentsel politika koyucularm, yerel yönetimlerin ve kentsel ulaşım alanında çalışma yapanlar yönlendirecek, özellikle toplu taşıma sistemleri ve taşıtları özelinde, kadın duyarlı ulaşım önceliklerinin geliştirilmesine yönelik öneriler sunmaktadır. Çalışma kapsamında Viyana, Berlin ve Malmö kentlerindeki örneklerin incelenmesi ve Ankara'da 2013 yılında gerçekleştirilen hanehalkı anketlerinden elde edilen verilerle, bir büyükşehirde yaşayan kadın nüfusunun ulaşım davranışları değerlendirilerek, kadın duyarlı ulaşımı destekleyen önerilerin geliştirilmiştir.

Anahtar Kelimeler: Cinsiyet duyarlı ulaşım, politika üretimi, yolculuk amacl, yolculuk süresi 


\title{
Determining of Women-Sensitive Transportation Approach and Policy Production: The Case of Ankara
}

\begin{abstract}
Nowadays, the time spent in urban transportation varies from the point of view of urban physical space, depending on the development of land use and transportation infrastructure. From the individual point of view, the most important indicator of the difference in travel time can be considered as gender, age group, type of transport used, travel chain and travel purpose. Women and men of different age groups, traveling for different journeys, using different types of transportation, travels in different times. By ignoring these differences, local governments assume a similar level of urban mobility by assuming that each individual has a similar urban mobility, and they offer a certain level of public transport service with a priority for a male-dominated society. This negatively affects the daily mobility of women and restricts women's participation in urban life and the city's mobility. This study provides recommendations for the development of women-sensitive transport priorities, in particular for public transport systems and vehicles, which will guide urban policy makers, local authorities and those working in urban transport. The aim of this study is to examine the sample practices in the cities of Vienna, Berlin and Malmö, and to support the suggestions by evaluating the transportation behaviors of the women living in a metropolitan city with the data obtained from the household surveys conducted in 2013 in Ankara.
\end{abstract}

Keywords: Gender-sensitive transportation, policy production, travel purpose, travel time 


\section{Giriş}

Gelişmiş ya da gelişmekte olan birçok ülkede yaşanan en önemli kentsel problemlerden birisi ulaşım ve ulaştırma alanındadır. Bu problemin temelinde, kentsel nüfusun artışına bağlı hızlı kentleşme ve ulaşımda motorizasyonun önlenemez artışı yatmaktadır. Yaşadığımız hızlı kent hayatı, yaş, sosyal statü ve cinsiyet ayrımı olmaksızın toplumun her kesimini olumsuz yönde etkilemektedir. Kentlerimiz, erkek egemen bir toplumu referans alarak planlanmakta ve kente yönelik her türlü fonksiyon bu bağlamda tasarlanmaktadır. Bu durum karşısında kadınlar, çocuk, yaşlı ve engellilerin de dâhil olduğu dezavantajlı grubun ulaşım öncelikleri çoğu kentte göz ardı edilmektedir. Bu grup içerisinde kadınlar, hem çocuk, hem anne hem de bir yaşlı olarak her yaş grubunda da ulaşım sorununu en yoğun yaşayan bireylerdir ve her türden ulaşım sorununa öncelikli olarak çözüm üretilmesi gereken kentli nüfusu oluşturmaktadır.

Kadının toplumdaki yeri, iş alanı, eğitim imkânlarının gelişmesi, bakmakla yükümlü olduğu çocuk, yaşlı ya da hasta bireylerin bulunması, gün içindeki hareketlilik zamanının değişkenlik göstermesi ile artık kentlerimiz kadın egemenliğine evrilen bir yapıya dönüşmektedir. Bu bağlamda, kentsel ulaşımda kadının ulaşım deseninin sorgulanmasının temel amacı, kadının gün içerisinde güvenli şekilde ulaşım sağlamasının, bu ulaşım talebinin ve beklentisinin karşılanmasına yönelik toplumsal algının ortaya koyulması ve bu hususlara dikkat çekmeyi sağlamaktır. Sosyal statü, ekonomik koşullar ve demografik yapı kadının yolculuk davranışlarını etkileyen birincil etmenlerdendir (Bosoni, 2014; Uteng, 2011; Chapple, 2001). Bu etmenler, farklı yaş grubundaki kadınların yolculuk amacı ve süresinde farklılığa neden olur. Aile yapısı, çalışma koşulları ve yaş grubu, kadının iş imkanlarını, gelir düzeyi ve kent içi hareketliliğini etkilemektedir. Çalışmama durumu, düşük ücretli veya yarı zamanlı çalışma, engelli olma durumu ve bakmakla yükümlü olunan kişilerden dolayı, kadının kent içindeki günlük hareketliliği gün içerisinde daha kısıtlı olabilmektedir. Kadının kentsel yaşama aktif katılımının sağlanması ve kentsel hareketliliğine yönelik beklentisi, Dünya kentlerindeki ulaşım öncelikleriyle birlikte ele alınarak değerlendirilmesi önemli bir husustur. 
Yolculuk deseni, fiziki ve zamansal kombinasyona bağlı değişkenlik gösteren bir düşünce sisteminin ürünüdür. İnsan aktivitelerine bağlı olarak meydana gelen bu yolculuk deseni, özellikle konu taşıt trafiği olduğunda, varış yerine mümkün olduğunca kısa sürede ve herhangi bir olumsuz duruma ihtimal vermeden hızlı erişimi temel alır (Monat, 2018). Ancak herkesin hizlı erişimi amaçladığı bir yolculuk deseninde, aynı zaman diliminde çıkılan yolculuklar birbirini engelleyerek, ulaşım süresinin daha da uzamasına neden olur. Ulaşım süresinin uzaması, günlük yolculukların analiz edilerek yolculuk süresi ve amaçlardaki farklılıkların ortaya koyulması ile önlenebilir. Ulaşım desenini farklılaştıran temel göstergeler, zaman, gelir, yaş, eğitim düzeyi, hanehalkı büyüklüğü ve yapısı, konum-sosyal statü, sorumluluklar, istihdam imkânı, güvenlik ve engellilik düzeyi; arazi kullanım deseni ve ulaşım imkânlarını kapsayan yapılı çevre; hareketliliğin sosyal, kültürel, teknolojik alt yapısı ile politik ve ekonomik coğrafyası olarak belirtilmektedir (Uteng, 2011; Kaufmann, 2002; Law, 1999).

Kişiler farklı gerekçelerle herhangi bir yolculuk gerçekleştirmezken, bazıları da sorumlulukları gereği birden çok yolculuk yapmakta, hatta çok uzun mesafeli, farklı amaçlar dâhilindeki yolculuklara katlanmaktadır. Literatür incelendiğinde, farklı yaş gruplarındaki kadın ve erkeklerin yolculuk deseninde de farklılık olduğu gözlenmiştir (Helling, 2004; Boumans ve Harms, 2004).

Cao ve Mokhtarian'a göre (2004) yaş ve cinsiyete dayalı yolculuklarda farklılaşmanın yanı sıra, çocuk sahibi olma, gelir durumu ve yaşam döngüsüne göre de yolculuk deseninde farklılık gözlenmiştir. Kadınlar, çocuk bakma sorumluluğundan dolayı, geliri düşük olsa dahi, hanelerine daha yakın olan işleri tercih etmekte, iş amaçlı yolculuk sürelerini minimize ederek, iş dışı aktiviteye daha fazla zaman ayırmaktadır (Chapple, 2001; Gordon ve diğerleri, 1989).

Law'ın ulaşım davranışları ve politikaları üzerine yaptığı çalışmaya göre (1999) kadınların yolculuk süresi erkeklere kıyasla daha kısa sürer. Erkekler tek bir amaçla yolculuk yaparken kadınlar daha kompleks ve farklı amaçlarla birden fazla yolculuk gerçekleştirmektedir (Turner ve Grieco, 2000). Kadınların günlük hayata katılımı günümüzde değişkenlik gösterse de bu durum kadının çocuk bakma ve hasta ya da yaşlı bakımı gibi roller üstlenmesinde bir değişikliğe neden olmamıştır (Bosoni, 2014). Kadınlar ev işleriyle ve aile bi- 
reyleriyle ilgilendikleri için daha kısa ve daha sık yolculuk yapmak durumunda kalmakta, böylece daha karmaşık bir ulaşım zinciri talebi ortaya çıkar (Lu ve Pas, 1998; Gordon ve diğerleri, 1989). Bu nedenledir ki erkekler daha doğrusal bir yolculuk desenine sahipken, kadınlar doğrusal olmayan zigzaglar içeren yolculuk desenine göre kentsel ulaşımda yerini alır (CIVITAS, 2015, s.20).

Kadınlar kentsel ulaşımda yolcu olarak rol alması erkelere kıyasla daha fazla olmaktadır. Kadınların yaya olarak yaptığı yolculuklar genelde belirli bir düzeyde sabit kalırken, yaşın artmasıyla birlikte toplu taşıma kullanım oranında artış yaşanmaktadır (Noble, 2000). Birleşmiş Milletler'nin yaptığ 1 çalışmalara göre kadınlar kentsel yolculuklarda \%73.9 oranında toplu taşımayı kullanmaktadır (UN, 2016).

Birçok ülkede olduğu gibi İskoçya'da da şiddet ve tehlikeli bir duruma maruz kalma korkusu, kadınların havanın karanlık olduğu geç saatlerde toplu taşımayı kullanma taleplerini etkilemekte, bu durum kadınları geç saatlerde otomobil kullanmaya yönlendirmektedir (Granville ve CampbellJack, 2005). İskoçya'da 60 yaşın altındaki kadınların özel otomobilli yolculukları daha fazladır (Li ve diğ., 2012).

Amerika'da yapılan Zaman Kullanım Anketine göre (BLS, 2003) 18 ve üzeri yaştaki genç ve yetişkin çalışan kadınlar, aynı yaş grubundaki çalışan erkeklere kıyasla haneyle ilgili aktivitelere ve aile üyeleriyle ilgili görevlerine daha fazla zaman ayırmaktadır. Böylece kadınların işyerine git-gel mesafesi kısalmakta, bu durum eve ya da alışverişe ayırdığı zamanı artırmaktadır. Li ve diğerlerine göre (2004) özellikle iş amaçlı yolculuklarda erkeklerin ortalama yolculuk süresi 32,05 dakika olarak ölçülürken kadınların ortalama yolculuk süresi 29,58 olarak ölçülmüştür. Bu sonuç, iş amaçlı yolculuklarda, kadınların daha kısa yolcuk süresi ortalamasına sahip olduğunu destekler niteliktedir.

Dünyada birçok kentte, cinsiyet duyarlı ulaşım önceliklerinin temel alındığı ulaşım planlaması uygulamaları yapılmaktadır. Ulaşım hizmetinin cinsiyet eşitliği bağlamında ele alınması, çevreye dost ulaşım türlerinin öncelikli tercih edilmesi, kadın, çocukve yaşlı bireylerin güvenli ve özgür bir şekilde kentsel ulaşımlarının sağlanabileceği altyapıların yeniden düzenlenmesi, ulaşıma ilişkin karar alınması süreçlerinde toplu taşımayı kullanan çeşitli grupların görüşüne başvuurlması bu önceliklere örnek teşkil edebilir.

İsveç, Malmö'de 1990'l1 yıllardan bu yana, Ulaşım ve İletişim Teknolojilerinde Cinsiyet Eşitliği Konseyi'nce toplu ulaşım politikalarında cinsiyet eşitliği 
yaklaşımı temel alınarak ulaşım politikaları üretilmektedir. Kadın ve erkeğin ulaşım önceliklerinde eşitlik bakış açısıyla erişilebilir, güvenli, yüksek kaliteli ulaşım imkânlarının artırılmasını benimseyen yaklaşımlar esas alınmıştır. Kadınların ulaşım taşıtlarında ve istasyonlarda kendini güvenli hissedeceği ve özel ihtiyaçları için yardım gerektirecek durumlar için, acil durum butonları konumlandırılmıştır. İsveç'te, kadınlar erkeklere kıyasla küçük otomobilleri daha fazla tercih etmektedir (Kronsell ve diğ., 2016; Aldred ve diğ., 2017). Elektrikli otomobillerde ise benzer bir durum söz konusudur ve kadınlar erkeklere kıyasla daha fazla elektrikli otomobil kullanmaktadır (Vassileva ve Campillo, 2017; CIVITAS, 2015).

Avusturya, Viyana'da 2005 yılından bu zamana kadar kadın-yaşlı-çocuk dostu çevre ve ulaşım için temel tasarım ilkeleri uygulanmaktadır. Sokak mekânının paylaşımı: güvenliği artırmak için okul, kreş ve kamusal alanlarda geniş kaldırımlar, bariyersiz yaya alanları, güvenli geçiş uygulamasına yönelik öncelikler belirlenmektedir. Almanya Berlin'de ise 2005 yılından beri birçok farklı alanda, cinsiyet duyarlı ulaşım planlama çalışmaları yapılmaktadır. Toplu taşımaya erişebilirlik: okul ve hastane gibi kamusal alanlara kısa yolculuk mesafesi ve süresini temel alan uygun ulaşım türü bağlantıları geliştirilmekte; toplu taşıma durakları ve bina girişlerinin sosyal kontrol amaciyla ticari kullanımlara yakın ve entegre tasarlanması ilkesi benimsenmektedir. Meksika'da toplu taşıma taşıtlarındaki güvenli olmayan koşulları nedeniyle, sadece kadınların kullanımına özel pembe metro ve pembe otobüs uygulamaları ön plandadır (Mejia-Dorantes, 2018; Dunckel-Graglia, 2013; Polk, 2008; CIVITAS, 2015).

Bütün bu kentlerdeki temel amaç, cinsiyet eşitliği bakış açısıyla ulaşımerişim imkânlarının geliştirilmesi ve her kesimden bireye fırsat eşitliği sağlanmasıdır. Ülkemizde ise kadın duyarlı ulaşım önceliklerinin geliştirilmesi ve politika üretimi için Ankara örneğinden hareketle geliştirilecek öneriler, bu önerilerin Türkiye'deki diğer kentlerde de uygulanabilirliği açısından önemli düzeyde yönlendirici rol oynayacaktır.

\section{Yöntem ve Metot}

Bu çalışmada, 2013 yılında Ankara'da gerçekleştirilen kentsel yolculuk araştırması (AUAP, 2014) ile elde edilen yolculuk deseni ve günlük yolculuk ta- 
leplerine yönelik uygulanan anket verileri kullanılmıştır. Hane halkı araştırması kapsamında toplanan kentsel yolculuk verileri; cinsiyet, yaş grupları, yolculuk amaçları ve yolculuk yapılan ulaşım türleri şeklinde gruplandırılmıştır. Bu veriler, tek yönlü varyans analizi tekniği kullanılarak analize tabi tutulmuştur. Çalışmada, kadın ve erkeklerin ulaşım türü tercihleri, yolculuk amaçları ve sürelerinin karşılaştırılmasına genel anlamda yer verilmiştir. Ayrıca, 6-14 yaş arası çocuk, 15-24 yaş arası genç, 25-40 yaş arası genç-orta yaş, 41-64 yaş arası orta yaş ve 65 yaş üstü yaşlı grup olarak belirlenen yaş gruplarındaki kadınların yolculuk amacı ve sürelerindeki farklılıklar ayrıntılı olarak ortaya koyulmuştur.

Ankara hanehalkı araştırmasında (AUAP, 2014), Ankara nüfusu genelinde \%3 örneklem oranı ve \%95 güven aralığında, 46.057 hane ile yapılan anket çalışması neticesinde 123.777 kişinin yolculuk bilgisi toplanmıştır. $\mathrm{Bu}$ kişilerce gerçekleştirilen tüm yolculuklar değerlendirildiğinde, toplam yolculuk miktarı 159.448'dir. Yapılan analizler, bu yolculuklar arasındaki farklılıklar üzerinden değerlendirmeye tabi tutulmuştur.

\section{Bulgular}

Ülkemiz kentlerinde, kadın duyarlı ulaşım önceliklerinin geliştirilmesi için, Ankara kent bütününde yapılmış hane halkı anketleri kapsamındaki bireysel yolculuklar temel alınarak bireysel ulaşım davranışlarının ortaya koyulması, önemli bir veri sağlayacaktır. Genel olarak yolculuk gerçekleştirenlerin demografik yapısı incelendiğinde, katılımcıların \%51,76'sı erkek, \%48,24'ü kadındır. Ancak toplam yolculuk sayısına bakıldığında, kentsel yolculukların \%61,5'i erkek, \%38,5'i kadınlar tarafından gerçekleştirilmektedir. Kadın yaş gruplarında en yüksek yolculuk oranı \%33,2 ile genç-orta yaş grubuna ait olup, ikinci sırada \%28,7 ile orta yaş grubu, üçüncü sırada ise \%25,6 ile genç yaş grubu gelmektedir. \%3,4 ile en az yolculuk oranına sahip olanlar yaşlılardir.

Günlük yolculukların ele alındığı hane halkı yolculuk davranışı anket çalışmasında, dokuz farklı yolculuk amacı belirtilmiştir. Bunlar; ev, iş, iş takibi, okul, arkadaş ziyareti, alışveriş, hastane-sağlık merkezi, sosyal-spor-eğlence ve diğer yolculuklar olarak belirlenmiştir. Ankara'da yapılan bu çalışmada, Tablo 1'de de belirtildiği üzere, kadın ve erkeklerin gerçekleştirdiği yolculuk 
amaçlarına bakıldığında, hem kadınların hem de erkeklerin ev varışlı yolculuklarının oranı $\% 48$ olarak gerçekleşmektedir. Her iki grup da aynı düzeyde yolculuklarını evde sonlandırmaktadır. Toplam yolculuk sayısı içerisinde kadınların \%13'ü erkeklerin ise \%26'sı iş amaçlı yolculuk gerçekleştirmektedir. Kadın ve erkeklerin iş amaçlı yolculuk oranlarındaki farklılıklar, erkeklerin, kadınlardan daha fazla iş hayatına katılım sağladığı yorumunu yapmamıza neden olabilir. Bu oranın, Türkiye İstatistik Kurumu tarafından belirlenen erkek ve kadın istihdam oranlarına (TÜİK, 2014) oldukça yakın olduğu görülmektedir.

Tablo 1. Yolculuk yapanların demografik yapısı

\begin{tabular}{llrr}
\hline Demografik veriler & & N & \% \\
\hline Cinsiyet & Kadın & 60.073 & 48,24 \\
& Erkek & 64.457 & 51,76 \\
\hline Toplam Yolculuk & Kadın & 61.366 & 38,5 \\
Sayısı & Erkek & 98.082 & 61,5 \\
\hline Kadınların Yaş & $6-14$ & 9.478 & 9,2 \\
Aralığ1 & $15-24$ & 14.043 & 25,6 \\
& $25-40$ & 19.199 & 33,2 \\
& $41-64$ & 16.460 & 28,7 \\
& 65+ & 2.186 & 3,4 \\
\hline Kadınların Yolculuk & Ev & 29223 & 47,62 \\
Ammacı & İş & 7811 & 12,73 \\
& Okul & 8440 & 13,75 \\
& İş Takibi & 319 & 0,52 \\
& Alışverişs & 4219 & 6,88 \\
& Sosyal spor eğlence & 3820 & 6,22 \\
& Hastane Sağllk Merkezi & 1983 & 3,23 \\
& Arkadaş Ziyareti & 3056 & 4,98 \\
& Diğer & 2495 & 4,07 \\
\hline
\end{tabular}

Kadın ve erkeklerin Avrupa Birliği ülkelerindeki ulaşım türü tercihleri Şekil 1'de belirtildiği üzere, kadınların yaya (\%19), bisikletli (\%9) ve toplu taşıma (\%23) imkânlarını daha çok kullanarak ulaşım gerçekleştirdiği gözlenmekte olup, sera gazı üretimi, enerji tüketimi ve iklim değişimini daha az etkileyen sürdürülebilir ulaşım türlerini tercih ettikleri gözlenmiştir. Erkeklerde ise daha çok özel oto kullanımı (\%58) ve motosiklet (\%3) gibi bireysel motorlu ulaşım türlerinin daha rağbet gördüğü belirlenmiştir. 


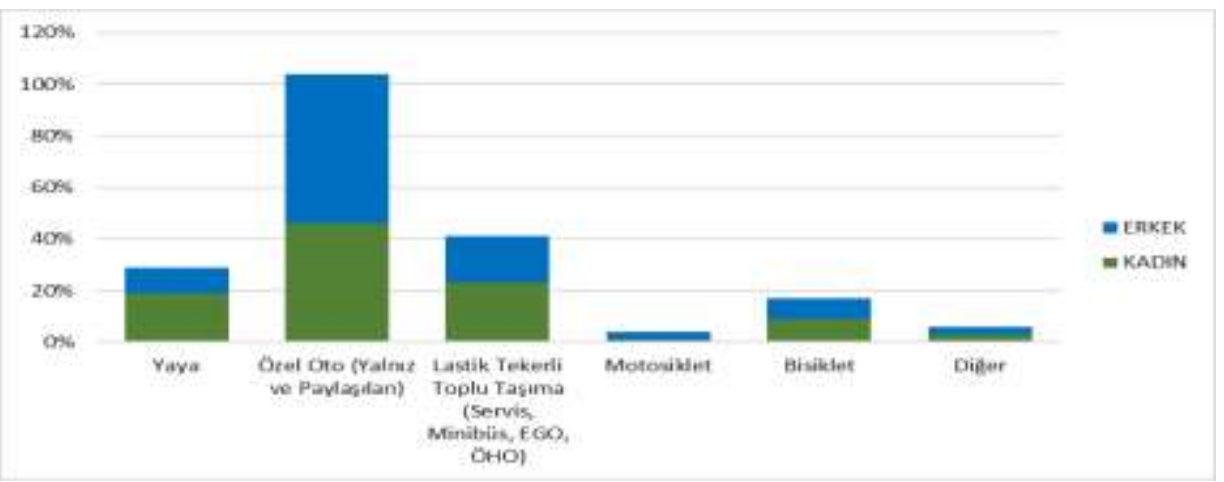

Şekil 1. Avrupa Birliği ülkelerinde (EU-27) cinsiyete göre ulaşım türü tercihleri (CIVITAS, 2015, s.44)

Kadın ve erkeklerin Ankara'daki ulaşım türü tercihleri Şekil 2'de görülmektedir. Buna göre Ankara'da kadınların yaya ulaşımında \% 35'lik oranla erkeklerin yaya ulaşımındaki \%26'lık oranını geride bıraktığı gözlenmiştir. Özel oto kullanımında erkekler \% 28 ile kadınlardan daha fazla özel araç kullanım oranına sahiptir. Kadınların özel oto kullanım oranının \% 18'lerde kalması, daha az emisyon üreten taşıt türlerini tercih etmesine; yaya ulaşımın yanı sıra, bireysel ulaşımda özel otoyu daha az kullanarak çevre dostu ulaşım türlerini tercih ettiğini göstermektedir. Kadın ve erkeklerden her iki grup da $\% 41^{\prime}$ lik oranla lastik tekerli toplu ulaşım türlerini kullanarak çevre kirliliği ve emisyon üretiminde eşit derecede rol oynadığı görülmektedir.

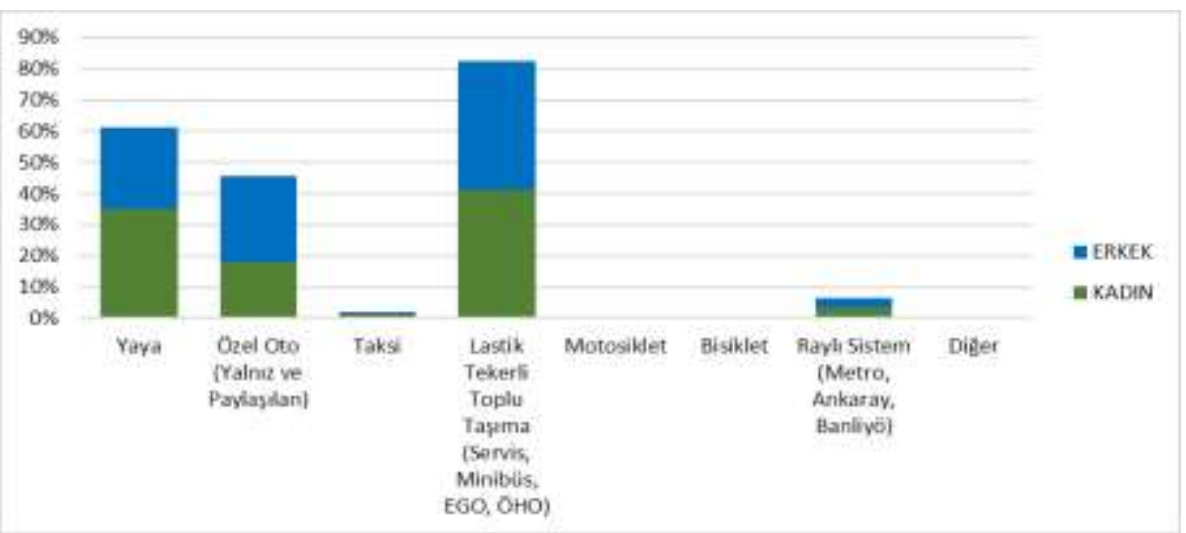

Şekil 2. Ankara'da cinsiyete göre ulaşım türü tercihleri (AUAP, 2014 ve Özkazanç, 2018, s.716'dan geliştirilmiştir) 
Kadın ve erkeklerin yolculuk desenleri incelenirken, tüm yolculuklar birlikte değerlendirildiğinde, ortalama yolculuk süreleri arasındaki farklılıklar gözlenmiştir. Tablo 2'de belirtildiği üzere, kentsel ulaşımda kadınların ortalama yolculuk süresi 33,81 dakikadır. Erkeklerin ortalama yolculuk süresi ise 36,26 dakika olarak hesaplanmıştır. Bu durumda erkeklerin kadınlara kıyasla kentsel ulaşımda 3,45 dakika daha fazla zaman harcadığı görülmektedir.

Kadınların yolculuk amaçlarına göre fazladan harcadığı süre değerlendirildiğinde, hastane-sağlik merkezi varışlı yolculuklarda 6,21 dakika, iş varışlı yolculuklarda 4,56 dakika ve iş takibi için 4,09 dakika daha fazla zaman harcadıkları görülmüştür. Erkeklerde ise fazladan harcanan süre kadınlara k1yasla daha az olmasına rağmen yine de hastane-sağlık merkezi varışlı yolculuklarda 2,87 dakika, iş varışlı yolculuklarda 2,61 dakika, iş takibi için ise 2,84 dakika fazladan zaman harcandığı ortaya çıkmıştır. Dolayısıyla, kadınlar erkeklerden daha kısa ve daha az miktarda yolculuk gerçekleştirmekte, ancak bazı yolcuk amaçlarında kadınlar, erkeklere kıyasla daha çok yolculuk gerçekleştirmiş olmaktadır. Bu yolculuklar alışveriş, hastane-sağlık merkezi ve arkadaş ziyareti gibi daha çok kadın grubun ailede öncelikle gerçekleştirmiş olacağı yolculuk amaçlarıdır. Bu yolculuk amaçları çocuklar için, hasta arkadaş ya da aile bireyleri için ve arkadaşlarla yapılan buluşma, özel gün ve toplantılar için yapılan yolculuk amaçları olabileceği şeklinde değerlendirilebilir.

Tablo 2. Kadın ve erkeklerin yolculuk amacına göre ortalama yaptı̆̆ı süre

\begin{tabular}{lcccccc}
\hline Yolculuk Amacı & $\mathbf{N}$ & $\begin{array}{c}\text { Kadın } \\
\text { Ortalama } \\
\text { süre } \\
\text { (dakika) }\end{array}$ & $\begin{array}{c}\text { Std. } \\
\text { Sapma }\end{array}$ & $\mathbf{N}$ & $\begin{array}{c}\text { Ortalama } \\
\text { süre } \\
\text { (dakika) }\end{array}$ & $\begin{array}{c}\text { Std. } \\
\text { Sapma }\end{array}$ \\
\hline Ev & 29223 & 35,08 & 28,319 & 46715 & 37,66 & 28,191 \\
İş & 7811 & 38,37 & 26,371 & 25367 & 38,87 & 26,042 \\
Okul & 8440 & 26,41 & 22,034 & 9372 & 26,6 & 21,857 \\
İş Takibi & 319 & 37,9 & 25,84 & 1125 & 39,1 & 29,298 \\
Alışveriş & 4219 & 28,85 & 23,365 & 3232 & 29,87 & 22,38 \\
Sosyal-spor-eğlence & 3820 & 32,1 & 25,47 & 5429 & 31,26 & 24,885 \\
Hastane-sağlık-merkezi & 1983 & 40,02 & 26,542 & 1260 & 39,13 & 26,547 \\
Arkadaş ziyareti & 3056 & 34,83 & 29,223 & 2511 & 36,93 & 29,792 \\
Diğger & 2495 & 33,87 & 28,729 & 3071 & 35,7 & 28,054 \\
\hline TOPLAM & 61366 & 33,81 & & 98082 & 36,26 & \\
\hline
\end{tabular}




\section{Tartışma ve Sonuç}

Yapılan bu çalışmayla, kentsel ulaşımda kadının yolculuk davranışlarının öncelikle ele alındığı ulaşım politikaları üretilmesi amacıyla, kentteki karar üretme mekanizmalarını, politika üreticileri ve ulaşımda sosyal bakış açısının ön planda tutulmasına yönelik araştırmacıları yönlendirecek görüş ve öneriler sunulmaktadır. Bu öneriler, sürdürülebilir ulaşım alanındaki ilkeler temel alınarak kadının hem bir anne, hem bir yaşlı hem de bir çocuk ya da engelli bir birey olma ihtimalini göz önünde bulundurarak, çevre duyarlı ulaşımını destekleyecek önlemlerin geliştirilmesi yönünde önerilerde bulunulmuştur. Bu bağlamda, ulaşım sistemi, ulaşım taşıtları, ulaşım önceliklerine ek olarak ulaşımın her alanında kadını merkeze alan kısa-orta ve uzun vadeli politikalar ve çözüm önerileri üretilmelidir. Bu öneriler özellikle sürdürülebilirlik bağlamı da düşünüldüğünde, daha az emisyon, daha az enerji tüketimi ve çevre kirliliğine neden olacak metro, banliyö, otobüs, bisiklet ve yaya ulaşımını birbirine entegre edecek toplu taşıma tür ve sistemlerinin teşvik edilmesi önceliğiyle şöyle değerlendirilebilir;

- Çalışmadan elde edilen veriler ışığında, ulaşım öncelikleri belirlenirken 25-40 yaş aralığındaki genç-orta yaş kadın nüfusun kentsel hareketliliğinin daha fazla olmasından hareketle bu yaş gruplar1nın yolculuk amaçlarına öncelikle eğilmek gerekmektedir. Bu yaş grubundaki kadınların özellikle okul, sosyal spor eğlence, alışveriş, hastane sağlık merkezi ve arkadaş ziyareti amacıyla yaptığı yolculukların (\%25), aynı yaş grubundaki erkeklerin bu amaçlarla yaptığı yolculuklardan (\%10) daha fazla olması nedeniyle aktif ve dinamik nüfusun yolculukları göz önünde bulundurulmalıdır.

- Çalışma kapsamında da belirtildiği gibi, kadınlar erkeklere k1yasla daha farklı amaçlarla yolculuk gerçekleştirmektedir. Bu bağlamda kadınların kentsel ulaşımda farklı amaçla yaptıkları çoklu yolculuklardaki erişim süresini azaltacak toplu taşıma aktarma imkânları ve otopark imkânları, özellikle alışveriş alanları, okul alanları, hastane-sağlık merkezi alanlarında geliştirilmelidir.

- Karma kullanımlı kent planları ile ulaşım planları entegre edilerek daha kısa süreli ve kolay ulaşım imkanlarının kadınlar için tercih edilebilirliği artırılmalıdır. 
- Kadınların bisiklet, yaya, toplu taşıma ve raylı sistemler gibi çevre dostu ulaşım türlerini kullanımını daha çok teşvik edecek uygun ücretlendirme politikaları uygulanmalı ve kadının kentsel hareketliliğe daha çok katılımı sağlanmalıdır.

- Kadınlar için özellikle çalışma kapsamında da belirtildiği üzere çocuğun okula bırakılıp alındığı, iş çıkışı alışveriş sonrası eve ulaşımın sağlandığı zirve saatlerde ve hastane-sağlık merkezine erişimin yoğunluklu olduğu zaman zarflarında taşıt paylaşımı ve toplu taşımadan daha uygun ücretle faydalanma imkânı sunan, aylık abonelikli indirimli kentkart uygulamaları yapılmalıdır.

- Güvenli taksi uygulaması ile birlikte, daha düşük ücret tarifeli, hem gündüz hem de gece boyunca hizmet verecek taksi imkânları teşvik edilmelidir.

- İyi aydınlatılmış (güneş enerjisi kullanımı önemli) ve görsel işaretlerle okunabilirliği artırılmış toplu taşıma durakları ile gündüz olduğu gibi gece de güvenlik sağlanmalıdır.

- Hızlı ve kolay erişimi sağlayan asansör ve yürüyen merdivenleri bulunan aktarma noktaları üretilmelidir.

- Kadınlar için ayrılmış, uygunsuz ortamları ve olası istismarı önlemek amacıyla iyi aydınlatılmış, yönlendirme levhalarının okunabilirliği yüksek ve kolay erişilebilir, özellikle giriş-çıkış noktalarına yakın konumlandırılmış otopark alanları üretilmelidir.

- Sürücüye ve acil durum iletişim araçlarına yakın alanda kadınlar için ayrılmış oturma birimleri olan, yol ile taşıt arasındaki kot farkını azaltan düşük zeminli, iç mekânında pusetler için uygun boş alana sahip, kör noktaları önleyecek donanımlara sahip toplu taşıma taşıtlarının üretilmesi ve teşvik edilmesi sağlanmalıdır.

- Toplu taşıma taşıtlarının iç tasarımında çocuklu, yaşlı ve engelli kadınlara ayrıcalık sağlayacak düzenlemeler yapılmalıdır.

- Akıllı ulaşım sistemlerinin kullanılması ile zamandan, mekândan ve mali olarak en üst düzeyde kazanç sağlanmalı ve kadının, ülkenin ekonomik gelişimini destekleyecek uygulamaları kullanarak, kentsel ulaşımda etkinliğini artırması sağlanmalıdır.

- Hepsinden önemlisi, kentlerde kadınların ulaşımda öncelikli olmasına yönelik farkındalığı artıracak eğitim, kamu spotu ve reklam kampanyaları ile kadına pozitif ayrımcılık sağlanmalıdır. 
Yerel yönetimler tarafından, kentsel ulaşımı ve hareketliliği kolaylaştıracak öncelikler alınmalı ve günün her saatinde güvenli ulaşım-erişimin hedef alındığı ulaşım sistemi alternatifleri üretilmelidir. Kadın duyarlı ulaşım politikalarının üretilmesi amacıyla, kadınların ulaşım davranışlarının ve kentsel ulaşım alışkanlıklarının dikkatli şekilde analiz edilmesi gerekmektedir. Kadınların farklı yaş gruplarında farklı yolculuk taleplerinde bulundukları, bu yolculuk taleplerini karşılarken ne kadar zaman harcadıkları, yolculuklarında hangi ulaşım türünü tercih ettikleri ve bu ulaşım türüne erişim kolaylıkları, ulaşım süresi boyunca güvenliği ve ulaşım konforunun sağlanması gibi husulara öncelikle eğilinmesi, bu yönde üretilecek ulaşım politikalarının, kadınların kentsel yoluluklarına nasıl uygun şekilde eklemlenebileceği hususu dikkatli şekilde değerlendirilmelidir.

Sonuç olarak, günümüz koşulları, çevresel değerlerin korunması ve ulaşım yapısının sürekliliğinin sağlanması bağlamında bakıldığında, kadının ulaşım önceliklerini belirleyerek politika geliştirilmesinde artık önemli olan, çevre dostu ve sürdürülebilir ulaşım planlama yaklaşımları geliştirerek kentte yaşayan diğer bireylerin de pozitif dışsallık sağlamasına katkıda bulunmak gerekmektedir.

\section{Teşekkür}

Bu çalışmada, Gazi Üniversitesi Ulaşım Ana Planı Ofisi tarafından 31.01.2013 -28.07.2017 yılları arasında hazırlanan Ankara Metropoliten Alanı ve Yakın Çevresi Ulaşım Ana Planı Projesi kapsamında toplanan hanehalkı anketi verileri kullanılmıştır. Bu çalışmanın özeti, daha önce İzmir'de düzenlenen 2. Uluslararası Kadın Kongresinin, bildiri özetleri kitabında yer almıştır. 


\section{EXTENDED ABSTRACT}

\section{Determining of Women-Sensitive Transportation Approach and Policy Production:The Case of Ankara

\author{
Hatice Gül Önder \\ Ankara Hacı Bayram Veli University
}

Nowadays, the time spent in urban transportation varies from the point of view of urban physical space, depending on the development of land use and transportation infrastructure. From the individual point of view, the most important indicator of the difference in travel time can be considered as gender, age group, type of transport vehicle, travel chain and travel purpose. Women and men of different age groups, traveling for different journeys, using different types of transportation, travels in different times. By ignoring these differences, local governments assume a similar level of urban mobility by assuming that each individual has a similar urban mobility, and they offer a certain level of public transport service with a priority for a male-dominated society. This negatively affects the daily mobility of women and restricts women's participation in urban life and the city's mobility. This study provides recommendations for the development of women-sensitive transport priorities, in particular for public transport systems and vehicles, which will guide urban policy makers, local authorities and those working in urban transport. The aim of this study is to examine the sample practices in the cities of Vienna, Berlin and Malmö, and to support the suggestions by evaluating the transportation behaviors of the women living in a metropolitan city with the data obtained from the household surveys conducted in 2013 in Ankara.

One of the most important urban problems experienced in many countries today is in the field of transportation. The main reason behind this problem lies in the rapid inability of urbanization and the inevitable increase in motorization in transportation. The rapid urban life we live affects every segment of the society negatively, regardless of age, social status and gender. Our cities are planned with reference to a male-dominated society and all kinds of functions for the city are designed in this context. In the face of this situation, the transportation priorities of the disadvantaged group, including women, children, the elderly and the disabled, are ignored in most cities. 
Within this group, women, children, mothers, and elderly people are the most experienced individuals in all age groups, and they constitute the urban population that needs to be solved primarily for all kinds of transportation problems.

Our cities are transformed into a structure that has evolved into women's sovereignty with the place of women in the society, the field of work, the development of educational opportunities, the presence of children, elderly or sick individuals that are obliged to look after, and the time of mobility during the day varies. In this context, the main purpose of questioning the place of women in urban transportation is to meet the woman's need for safe transportation and expectations from transportation throughout the day, and to ensure that the necessary importance is given to the social acceptability of this situation with sensitivity.

Within the scope of this study, the data obtained from the household urban travel survey conducted in Ankara in 2013 was used. Urban travel data collected within the scope of the household survey; They are grouped as gender, age groups, travel purposes and types of transportation. These data were analyzed using one-way analysis of variance technique. In the study, the comparison of transportation type preferences, travel purposes and duration of women and men are given in general terms. In addition, the differences in the purpose and duration of travel of women in the age groups determined as children between the ages of 6-14, youth between the ages of 15-24, youthmiddle age between the ages of 25-40, middle age between the ages of 41-64 and elderly over the age of 65 are detailed. It was revealed as.

For the development of women's sensitive transportation priorities in the cities of our country, revealing individual transportation behaviors based on the individual journeys within the scope of household surveys conducted throughout Ankara will provide important data. When the demographic structure of those traveling in general is examined, $51.76 \%$ of the participants are male and $48.24 \%$ are female. However, considering the total number of trips, $61.5 \%$ of urban trips are performed by men and $38.5 \%$ by women. The highest travel rate in female age groups belongs to the young-middle age group with $33.2 \%$, the middle age group with $28.7 \%$ and the young age group with $25.6 \%$. Those who have the lowest travel rate with $3.4 \%$ are the elderly.

With this study, suggestions are produced to produce urban sensitive transportation policy in urban transport, to direct urban decision-making 
bodies, politicians and researchers on the social context of transportation. While producing these suggestions, suggestions were made to develop measures to support environmentally sensitive transportation, taking into account the possibility of the woman being both a mother, an elderly, a child or a disabled individual, based on the principle of sustainability.

\section{Kaynakça / References}

Aldred, R., Elliott, B., Woodcock, J., ve Goodman, A. (2017). Cycling provision separated from motor traffic: a systematic review exploring whether stated preferences vary by gender and age. Transport Reviews, 37(1), 29-55.

AUAP-Ankara Ulaşım Ana Planı (2014). Ankara metropoliten alanı ve yakın çevresi ulaşım ana planı hanehalkı araştırması, Ankara: Ulaşım Plan Ofisi.

Bosoni, M. L. (2014). "Breadwinners" or "Involved Fathers?" Men, fathers and work in Italy. Journal Of Comparative Family Studies, 45(2), 293-315.

Boumans, A. ve Harms, L. (2004). Part-time employment and travel patterns of women in the Netherlands. Research on Women's Issues in Transportation Report of Conference, Volume 2: Technical Papers, 113.

BLS-Bureau of Labor Statistics (2003). American time use survey. U.S. Department of Labor.

Cao, X., ve P. Mokhtarian. (2004). How do individualsmanage their personal travel? objective and subjectiveinfluences on the consideration of travel-relatedstrategies. Presented at 83rd Annual Meeting of theTransportation Research Board, Washington, D.C.

Chapple K, (2001). Time to work: job search strategies and commute time for women on welfare in San Francisco. Journal of Urban Affairs, 23, 155-173.

CIVITAS (2015) Policy Notes: Smart choices for cities gender equality and mobility: mind the gap! 25.09.2019 tarihinde https://civitas.eu/sites/default/files/civ pol-an2 m web.pdf adresinden erişilmiştir.

Dunckel-Graglia, A. (2013). Rosa, el nuevo color del feminismo: un análisis del transporte exclusivo para mujeres. La Ventana. Revista de Estudios de Género, 4(37), 148-176.

Gordon, P., Kumar, A. ve H. Richardson. (1989). Gender differences in metropolitan travel behavior. Regional Studies, 23(6), 499-510. 
Granville, S., ve Campbell-Jack, D. (2005). Anti-social behaviour on buses. Scottish Executive Social Research. 11.10.2019 tarihinde https://www.webarchive.org.uk/wayback/archive/20180518065257/ http://www.-gov.scot/Publications/2005/03/20783/53886 adreslerinden erişilmiştir.

Helling A. (2004). Connection between travel and physical activity differences by age and gender.Research on Women's Issues in Transportation Report of Conference, Volume 2: Technical Papers, 76-77.

Kaufmann V. (2002.) Re-thinking mobility. Aldershot: Ashgate.

Kronsell, A., Smidfelt Rosqvist, L., ve Winslott Hiselius, L. (2016). Achieving climate objectives in transport policy by including women and challenging gender norms: The Swedish case. International Journal Of Sustainable Transportation, 10(8), 703-711.

Law R, (1999). Beyond 'women and transport': towards new geographies of gender and Daily mobility" Progress in Human Geography, 23(4) 567-588.

Li, H. Guensler R. ve Ogle, J. (2004). Comparing women's and men's morning commute trip chaining in Atlanta, Georgia, by using instrumented vehicle activity data. Research on Women's Issues in Transportation Report of Conference, Volume 2: Technical Papers, 14-20.

Li, H., Raeside, R., Chen, T., ve McQuaid, R. W. (2012). Population ageing, gender and the transportation system. Research in Transportation Economics, 34(1), 39-47.

Lu X. ve Pas E, (1998). Socio-demographics, activity participation and travel behavior. Transportation Research Part A, 33, 1-18.

Mejia-Dorantes, L. (2018). An example of working women in Mexico City: How can their vision reshape transport policy? Transportation Research Part A: Policy and Practice, 116, 97-111.

Monat, J. P. (2018). Explaining natural patterns using systems thinking, American Journal of Systems Science, 6(1), 1-15.

Noble, B. (2000). Travel characteristics of older people. Transport Trends,2000,9-25.

Özkazanç, S. (2018). Analysis of urban transportation in the context of gender: The case of Ankara. Recent Researches in Science and Landscape Management içinde, UK: Cambridge Scholars Publishing.

Polk, M., (2008). Gender mainstreaming in Swedish transport policy. (Uteng, T.P., Cresswell, T. Editör), Gendered Mobilities içinde (s.229-243) . Ashgate, Aldershot,

TÜIKK (2014). Hanehalkı işgücü istatistikleri. Ankara:TÜIK Haber Bülteni. 
Turner, J., ve Grieco, M. (2000). Gender and time poverty: the neglected social policy implications of gendered time, transport and travel. Time \& Society, 9(1), 129-136.

UN Women, (2016). Improving women's safety in Mexico City. 11.10.2019 tarihinde https://www.unwomen.org/en/news/stories/2016/11/improving-womens-safety-in-mexico-city adresinden erişilmiştir.

Uteng, T. P. (2011). Gender and mobility in the developing world: background paper-part i-gendered daily mobility. World Development Report 2012: Gender Equality and Development, 4-17.

Vassileva, I., ve Campillo, J. (2017). Adoption barriers for electric vehicles: Experiences from early adopters in Sweden. Energy, 120, 632-641.

\section{Kaynakça Bilgisi / Citation Information}

Önder, H. G. (2020). Kadın duyarlı ulaşım önceliklerinin belirlenmesi ve politika üretimi: Ankara örneği. OPUS-Uluslararası Toplum Araştırmalarn Dergisi, 15(23), 1993-2010. DOI: 10.26466/opus. 632122 